\title{
Hereditary Neuropathy with Liability to Pressure Palsy Presenting as an Acute Brachial Plexopathy: A Lover's Palsy
}

\author{
Sarah Wedderburn ${ }^{\mathrm{a}} \quad$ Puraskar Pateria $^{\mathrm{b}}$ \\ Peter K. Panegyres ${ }^{a, b}$ \\ ${ }^{a}$ Neurodegenerative Disorders Research Pty. Ltd., West Perth, W.A., and \\ ${ }^{b}$ Neurology Unit, Joondalup Health Campus, Joondalup, W.A., Australia
}

\section{Key Words}

Lover's palsy $\cdot$ Hereditary neuropathy $\cdot$ Pressure palsy $\cdot$ Brachial plexopathy

\begin{abstract}
It is generally regarded that patients with hereditary neuropathy to pressure palsies, due to a deletion in the PMP22 gene, show recurrent pressure palsy and generalised peripheral neuropathy (pes cavus and hammer toes sometimes develop). Brachial plexopathy is rarely identified as a first presentation of hereditary neuropathy to pressure palsies. We describe a young man who developed a painless flail upper limb with a clinical diagnosis of a brachial plexopathy after his partner slept on his arm - a PMP22 deletion was found. His father, who had a symmetrical polyneuropathy without recurrent mononeuropathies, shared the PMP22 deletion.

(C) 2014 S. Karger AG, Basel
\end{abstract}

\section{Introduction}

Hereditary neuropathy to pressure palsy (HNPP), also known as tomaculous neuropathy, is an autosomal dominant disorder with recurrent sensory and motor nerve palsies. Approximately $80 \%$ of HNPP cases are caused by a $1.5-\mathrm{Mb}$ deletion in chromosome 17 p11.2-12 of the myelin protein 22 gene (PMP22) [1, 2]; the remaining $20 \%$ of cases are accounted for by point mutations [3]. PMP22 encodes for a membrane glycoprotein that is 
Wedderburn et al.: Hereditary Neuropathy with Liability to Pressure Palsy Presenting as an Acute Brachial Plexopathy: A Lover's Palsy

expressed mainly in Schwann cells and, although minor, is an essential part of the compact myelin in peripheral nerves [4].

The prevalence of HNPP was reported as $2-5$ per 100,000 in a European study [3], and the disease usually manifests after the first two decades of life - childhood cases have been reported $[1,5]$. Individuals tend to present with a segmental neuropathy after trivial trauma or compressions, such as crossing their legs for a long period of time [6]. Prognosis is invariably good, with the majority of patients making a full or nearly full recovery within the space of a few months. Symptomatic treatment is the mainstay of management, where the aim is to prevent nerve compression [5].

HNPP is probably under-recognised and under-diagnosed. To emphasise the importance of this cause of hereditary brachial plexopathies, we describe a young man who presented with a left brachial plexopathy.

\section{Case Presentation}

In August 2010, a 30-year-old male financial adviser presented to the hospital having awoken with painless weakness and patchy numbness of his left upper limb. He had slept the previous night with his girlfriend sleeping on his left shoulder. Prior to this, he had been well without any significant neurological disease. His 59-year-old father had been diagnosed with Parkinson's disease 5 years ago and had peripheral neuropathy as well as carpal tunnel syndrome. He also had a 32-year-old sister who was in good health.

On examination, he was a tall, lean man, with a height of $195 \mathrm{~cm}$. He had weakness of the muscles of the proximal left upper limb, particularly the shoulder girdle. He was unable to abduct his left shoulder and had weakness on elbow flexion. Maximum weakness was observed in the supraspinatus, infraspinatus, deltoid, rhomboid, and triceps muscles, with a relative sparing of other muscles in the distal upper limb. Reflexes were preserved. The working diagnosis was that of a brachial plexopathy.

The MRI scan of his spinal cord and brachial plexus, performed pre- and postgadolinium, were normal. Nerve conduction studies, which were performed on August 9 2010, indicated an underlying peripheral neuropathy with mixed features to suggest an axonal and demyelinating polyneuropathy (table 1). Median and ulnar sensory nerve action potentials (SNAPs) recorded using both palmar stimulation and ring electrodes were absent. The radial SNAP was also absent. The distal median motor latencies were mildly prolonged bilaterally with borderline conduction velocities; F-waves prolonged in latencies on the right and absent on the left. The ulnar motor studies showed borderline distal motor latencies from stimulation at the wrist, mild slowing of conduction in the forearm without slowing above the elbow segments on both sides (data not shown); the F-waves revealed a latency prolongation - more marked on the left than on the right. Right common peroneal response showed a mildly prolonged distal motor latency from stimulation at the ankle with reduced amplitude and moderate slowing of conduction in the leg. F-waves were prolonged in latency, even when considering the patient's height. Right posterior tibial response had a normal latency, amplitude, and moderately reduced conduction velocity with prolongation of the Fwave latencies. Both right medial plantar and right sural SNAPs were absent. The F-wave prolongations were not consistent with the patient's height of $195 \mathrm{~cm}$ (where relevant).

Electromyography (EMG) showed a markedly reduced recruitment pattern, without features suggestive of active denervation, in most of the muscles sampled, in particular the left deltoid, abductor digiti minimi, supraspinatus, and rhomboid muscles. His father's nerve 
Wedderburn et al.: Hereditary Neuropathy with Liability to Pressure Palsy Presenting as an Acute Brachial Plexopathy: A Lover's Palsy

conduction studies also showed a mixed picture compatible with axonal degeneration and demyelination.

The clinical picture, nerve conduction studies, and EMG raised the possibility of HNPP as a diagnosis, and gene testing confirmed a PMP22 deletion on chromosome 17. Advice was given in regard to the protection of nerves from external pressure, in particular, avoiding his partner leaning or sleeping on his arms, not leaning his elbows on chairs or desks, and avoiding below-knee boots which might compress the common peroneal nerves below the fibula heads. He was also informed about the genetic nature of HNPP. A genetic review was organised, and as the patient expressed an interest in discussing family planning issues, particular emphasis was placed on advising about the genetic risk to his children as well as the implications of HNPP. Written informed consent was obtained from the patient for the publication of this case report.

\section{Discussion}

The first published description of HNPP was in 1947 by De Jong (in Hooper et al. [7]). Initial onset of the disease is generally painless and acute in the majority of cases (85\%) [3]. Typically, a patient will present with peripheral neuropathy, with superficial nerves being affected more often than deep nerves [1]. Some commonly affected nerves are the peroneal, ulnar, and radial nerves, accounting for 35,20 , and $8 \%$ of cases, respectively [5]. Progressive weakness may also be a presenting feature, and on examination, tendon reflexes may be reduced or absent; pes cavus and skeletal abnormalities may also be observed [3]. It is worth noting that the clinical picture of patients with HNPP may be misdiagnosed as CharcotMarie-Tooth disease type 1A (CMT1A) [8] and, interestingly, when examining the genetics of CMT1A, a duplication is present in chromosome $17 \mathrm{p} 12$, where a deletion will cause HNPP [9].

An electrophysiological investigation revealed findings characteristic of HNPP: prolonged distal motor and F-wave latencies, mildly reduced motor and sensory conduction velocities, reduced amplitudes of SNAPs, and a segmental slowing of conduction at the usual entrapment sites $[2,5]$. Compound muscle action potential amplitudes may be decreased; this may be due to a failure to maintain myelin stability [1]. It has also been reported that, independent of entrapment neuropathies, HNPP electrophysiological findings might show a background polyneuropathy, as shown in our patient [2].

Pathological findings of nerve biopsies in HNPP individuals usually show sausage-like swellings which are multi-focal thickenings of the myelin sheath [1,3] (called 'tomaculae'). However, nerve biopsies have largely been replaced by molecular genetic testing. Genetic testing has proven invariably useful in HNPP families, as up to $50 \%$ of individuals with the HNPP deletion are asymptomatic, with normal findings on clinical neurological examination [10]. The deletion reduces the normal function of myelin [11]. Sometimes, HNPP may also be due to PMP22 frame shift mutations, with patients developing more neuropathic features and mimicking hereditary sensory and motor neuropathy type 1 (CMT1A) [12]. HNNP must be distinguished from hereditary neurologic amyotrophy, which may present with recurrent familial painful brachial neuropathy [11].

Hereditary brachial plexus neuropathy, or hereditary neurologic amyotrophy (HNA), is an episodic debilitating painful condition of the shoulder girdle leading to amyotrophy that develops within 2 weeks of pain onset. Sensory symptoms may occur, including hypoaesthesia and paraesthesias, and dysmorphic features may be found (e.g., craniofacial, cleft palate, short stature, syndactyly). This is an autosomal dominant condition caused by mutations in 
Wedderburn et al.: Hereditary Neuropathy with Liability to Pressure Palsy Presenting as an Acute Brachial Plexopathy: A Lover's Palsy

the SEPT9 gene, a septin protein involved in cytokinesis, in about $55 \%$ of individuals with HNA; in $45 \%$ of HNA, the gene mutation is not detected and might relate to a deletion or duplication, or previously unrecognised gene mutations [13, 14].

HNA may be classified as HNA1 due to SEPT9 mutations; HNA2 is an autosomal dominant condition that might relate to SEPT9 mutations, but is characterised by incomplete remissions, persistent pain and weakness between attacks [15]. HNA3, which is not related to $17 \mathrm{q} 26$ and patients do not have SEPT9 mutations, is characterised by painful onset weakness with a complete resolution [14]. HNA4, which is usually a painless proximal upper limb syndrome, with lower motor neuron signs, which may show slow progression over many years, spread to the neck and legs and might result in respiratory failure - there may be antiasialo-GM1 antibodies [15, 16].

Large phenotypic variation in HNPP individuals has been observed [8], and this is illustrated in our family where the father had symmetrical polyneuropathy and the son presented with a brachial plexopathy. This variability in phenotypes might lead to misdiagnosis of HNPP [9]. Management of HNPP patients must include genetic counseling of the affected individual and discussions relating to family planning.

Although medical management is largely conservative, there is a potential role for ultrasound techniques. It has proven useful with the diagnosis of nerve entrapment syndrome, such as carpal tunnel syndrome, and there is potential for patient follow-up when nerve regeneration does not proceed [7]. Occasionally, surgical decompression of nerve entrapment might be necessary to aid recovery, with emphasis on careful intra-operative patient positioning in orthopaedic treatments involving traction or splinting and to prevent nerve compression $[1,5]$.

\section{Conclusion}

Awareness of HNPP among clinicians of both medical and surgical specialties is important, as there are many potential misdiagnosed or unrecognized acute cases. Emphasis on considering a diagnosis of HNPP in young individuals who repeatedly present with peripheral nerve palsies in very important; however, our case reveals that other presentations are possible.

\section{Disclosure Statement}

The authors declare that they have no competing interests.

\section{References}

1 Chua SY, Lim YW, Lam KS, Low CO: Hereditary neuropathy with liability to pressure palsies. Singapore Med J 2006; 47:625-626.

2 Casasnovas C, Banchs I, De Jorge L, Antonia Alberti M, Martinez-Campo Y, Povedano M, Montero J, Volpini V: A novel small deletion in PMP22 causes a mild hereditary neuropathy with liability to pressure palsies phenotype. Muscle Nerve 2012;45:135-138.

-3 Paprocka J, Kajor M, Jamroz E, Jezela-Stanek A, Seeman P, Marszal E: Hereditary neuropathy with liability to pressure palsy. Folia Neuropathol 2006;44:290-294.

4 Scherer SS, Wrabetz L: Molecular mechanisms of inherited demyelinating neuropathies. Glia 2008;56:15781589. 
Wedderburn et al.: Hereditary Neuropathy with Liability to Pressure Palsy Presenting as an Acute Brachial Plexopathy: A Lover's Palsy

5 Celik Y, Kilincer C, Hamamcioglu MK, Balci K, Birgili B, Cobanoglu S, Utku U: Hereditary neuropathy with liability to pressure palsies in a Turkish patient (HNPP): a rare cause of entrapment neuropathies in young adults. Turk Neurosurg 2008;18:82-84.

6 Koehler PJ: Hereditary neuropathy with liability to pressure palsies: the first publication (1947). Neurology 2003;60:1211-1213.

7 Hooper DR, Lawson W, Smith L, Baker SK: Sonographic features in hereditary neuropathy with liability to pressure palsies. Muscle Nerve 2011;44:862-867.

-8 Moszynska I, Kabzinska D, Sinkiewicz-Darol E, Kochanski A: A newly identified Thr99fsX110 mutation in the PMP22 gene associated with an atypical phenotype of the hereditary neuropathy with liability to pressure palsies. Acta Biochim Pol 2009;56:627-630.

9 Taioli F, Cabrini I, Cavallaro T, Acler M, Fabrizi GM: Inherited demyelinating neuropathies with micromutations of peripheral myelin protein 22 gene. Brain 2011;134:608-617.

-10 Infante J, Garcia A, Combarros 0, Mateo JI, Berciano J, Sedano MJ, Gutiérrez-Rivas EJ, Palau F: Diagnostic strategy for familial and sporadic cases of neuropathy associated with 17p11.2 deletion. Muscle Nerve 2001;24:1149-1155.

-11 Kuhlenbäumer G, Stögbauer F, Timmerman V, De Jonghe P: Diagnostic guidelines for hereditary neuralgic amyotrophy or heredofamilial neuritis with brachial plexus predilection. On behalf of the European CMT Consortium. Neuromuscul Disord 2000;10:515-517.

12 Lenssen PP, Gabreëls-Festen AA, Valentijn LJ, Jongen PJ, van Beersum SE, van Engelen BG, van Wensen PJ, Bolhuis PA, Gabreëls FJ, Mariman EC: Hereditary neuropathy with liability to pressure palsies. Phenotypic differences between patients with the common deletion and a PMP22 frame shift mutation. Brain 1998;121:1451-1458.

13 Kuhlenbaumer G, Hannibal MC, Nelis E, Schirmacher A, Verpoorten N, Meuleman J, Watts GD, De Vriendt E, Young P, Stogbauer F, Halfter H, Irobi J, Goossens D, Del Favero J, Betz BH, Hor H, Kurlemann G, Bird TD, Airaksinen E, Mononen T, Serradell AP, Prats JM, Van Broeckhoven C, De Jonghe P, Timmerman V, Ringelstein EB, Chance PF: Mutations in SEPT9 cause hereditary neuralgic amyotrophy. Nat Genet 2005;37:1044-1046.

14 Kuhlenbaumer G, Meuleman J, De Jonghe P, Falck B, Young P, Hunermund G, Van Broeckhoven C, Timmerman V, Stogbauer F: Hereditary neuralgic amyotrophy (HNA) is genetically heterogeneous. J Neurol 2001;248:861-865.

15 van Alfen N, van Engelen BG, Reinders JW, Kremer H, Gabreëls FJ: The natural history of hereditary neuralgic amyotrophy in the Dutch population: two distinct types? Brain 2000;123:718-723.

-16 Pestronk A, Chaudhry V, Feldman EL, Griffin JW, Cornblath DR, Denys EH, Glasberg M, Kuncl RW, Olney RK, Yee WC: Lower motor neuron syndromes defined by patterns of weakness, nerve conduction abnormalities, and high titers of antiglycolipid antibodies. Ann Neurol 1990;27:316-326.

17 Katz JS, Wolfe GI, Andersson PB, Saperstein DS, Elliott JL, Nations SP, Bryan WW, Barohn RJ: Brachial amyotrophic diplegia: a slowly progressive motor neuron disorder. Neurology 1999;53:1071-1076. 


\section{Case Reports in Neurology}

\begin{tabular}{l|l}
\hline \multicolumn{2}{l|}{ Case Rep Neurol 2014;6:281-286 } \\
\hline DOI: $10.1159 / 000369921$ & $\begin{array}{l}\text { C 2014 S. Karger AG, Basel } \\
\text { www.karger.com/crn }\end{array}$ \\
\hline
\end{tabular}

Wedderburn et al.: Hereditary Neuropathy with Liability to Pressure Palsy Presenting as an Acute Brachial Plexopathy: A Lover's Palsy

Table 1. Nerve conduction studies and EMG

\begin{tabular}{|c|c|c|c|c|c|c|c|c|}
\hline \multirow[t]{2}{*}{ Nerve conduction studies } & \multicolumn{4}{|c|}{ Distal latency, m/s } & \multicolumn{2}{|c|}{$\begin{array}{l}\text { Conduction } \\
\text { velocity, } \mathrm{m} / \mathrm{s}\end{array}$} & \multicolumn{2}{|c|}{$\begin{array}{l}\text { Amplitude, } \\
\mathrm{MV} / \mu \mathrm{V}\end{array}$} \\
\hline & \multicolumn{2}{|l|}{ right } & \multicolumn{2}{|l|}{ left } & right & lleft & right & left \\
\hline 2nd median sensory (P.I.S.) & $*$ & & $*$ & & $*$ & $*$ & $*$ & $*$ \\
\hline 4th ulnar sensory (P.I.S.) & $*$ & & $*$ & & $*$ & $*$ & $*$ & $*$ \\
\hline Radial sensory (forearm) & $*$ & & & & $*$ & & $*$ & \\
\hline Median ring electrodes (wrist) & $*$ & & & & $*$ & & $*$ & \\
\hline Ulnar ring electrodes (wrist) & $*$ & & & & $*$ & & $*$ & \\
\hline Median motor (wrist) & 5.4 & & 7.2 & & & & 8.2 & 10.2 \\
\hline Median motor (elbow) & 11.48 & & 13.32 & & 46.7 & 45.6 & 6.7 & 6.8 \\
\hline Median motor F-waves (wrist) & $37.4-45.0$ & 4/4) & $(0 / 4)$ & & & & & \\
\hline Ulnar motor (wrist) & 4.16 & & 3.84 & & & & 10.5 & 10.2 \\
\hline Ulnar motor (elbow) & 10.92 & & 10.8 & & 44.4 & 45.3 & 8.6 & 7.4 \\
\hline Ulnar motor F-waves & $34.2-34.7$ & 4/4) & $40.6-4$ & /4) & & & & \\
\hline Common peroneal (ankle) & 7.36 & & & & & & 1.4 & \\
\hline Common peroneal $(\downarrow$ knee $)$ & 20.08 & & & & 30.45 & & 0.8 & \\
\hline Common peroneal (knee) & 22.04 & & & & 49.49 & & 0.7 & \\
\hline Common peroneal F-waves (ankle) & $74.3-82.4$ & 4/4) & & & & & & \\
\hline Posterior tibial (ankle) & 5.16 & & & & & & 3.3 & \\
\hline Posterior tibial (knee) & 19.8 & & & & 32.1 & & 1.3 & \\
\hline Posterior tibial F-waves & $67.6-70.6$ & 4/4) & & & & & & \\
\hline Medial plantar & $*$ & & & & $*$ & & $*$ & \\
\hline Sural (calf; $140 \mathrm{~mm}$ ) & $*$ & & & & $*$ & & $*$ & \\
\hline \multirow[t]{2}{*}{ EMG } & \multirow[t]{2}{*}{$\begin{array}{l}\text { Insertion } \\
\text { activity }\end{array}$} & \multicolumn{2}{|c|}{$\begin{array}{l}\text { Spontaneous } \\
\text { activity }\end{array}$} & \multicolumn{2}{|c|}{$\begin{array}{l}\text { Recruitment } \\
\text { pattern }\end{array}$} & \multicolumn{2}{|l|}{ Motor units } & \\
\hline & & fibs & fascic & & & $\begin{array}{l}\text { motor } \\
\text { amplitude }\end{array}$ & $\begin{array}{l}\text { unit } \\
\text { duration }\end{array}$ & phases \\
\hline L. abductor digiti minimi $(\mathrm{C} 8, \mathrm{~T} 1)$ & $\mathrm{N}$ & - & - & -2 & & $\mathrm{~N}$ & LD & $\mathrm{N}$ \\
\hline L. first dorsal interosseous (C8,T1) & $\mathrm{N}$ & - & - & -1 & & $\mathrm{~N}$ & $\mathrm{~N}$ & $\mathrm{~N}$ \\
\hline L. abductor pollicis brevis (C8,T1) & $\mathrm{N}$ & - & - & -1 & & $\mathrm{~N}$ & $\mathrm{~N}$ & $\mathrm{~N}$ \\
\hline L. extensor digitorum communis $(\mathrm{C} 7,8)$ & $\mathrm{N}$ & - & - & full & & $\mathrm{N}$ & $\mathrm{N}$ & $\mathrm{N}$ \\
\hline L. biceps $(\mathrm{C} 5,6)$ & $\mathrm{N}$ & - & - & full & & $\mathrm{N}$ & $\mathrm{N}$ & $\mathrm{N}$ \\
\hline L. deltoid $(\mathrm{C} 5,6)$ & $\mathrm{N}$ & - & - & \multicolumn{5}{|c|}{ Markedly reduced recruitment } \\
\hline L. triceps $(\mathrm{C} 7,8, \mathrm{~T} 1)$ & $\mathrm{N}$ & - & - & -1 & & $\mathrm{~N}$ & $\mathrm{~N}$ & $\mathrm{~N}$ \\
\hline L. supraspinatus $(\mathrm{C} 5,6)$ & $\mathrm{N}$ & - & - & -2 & & $\mathrm{~N}$ & $\mathrm{~N}$ & $\mathrm{~N}$ \\
\hline L. cervical paraspinals & $\mathrm{N}$ & - & - & & & & & \\
\hline L. rhomboid $(\mathrm{C} 5,6)$ & $\mathrm{N}$ & - & - & -2 & & $\mathrm{~N}$ & $\mathrm{~N}$ & $\mathrm{~N}$ \\
\hline L. clavicular head of pectoralis major $(\mathrm{C} 5,6)$ & $\mathrm{N}$ & - & - & full & & $\mathrm{N}$ & $\mathrm{N}$ & $\mathrm{N}$ \\
\hline
\end{tabular}

* Absent/not detectable despite maximum stimulation, frequency, and amplitude. LD = Long duration. 